\title{
Ecological Construction of College Maker Education in the Internet Space based on VR Technology
}

\author{
Dong Yuanxiang*, Hou Chenjing, Li Peijun \\ School of Management Science and Engineering \\ Shanxi University of Finance and Economics \\ Taiyuan, P.R. China
}

\begin{abstract}
This paper constructs a new ecology for maker education based on the concept of "VR technology" and "Internet space". Firstly, the significance of VR technology and Internet space were systematically expounded, and were integrated in terms of development philosophy, educational resources, teacher and student roles and development opportunities. After the integration, the strategy of to promote the maker education in China includes: acquiring learning resources, building online counseling space and winning outside support. These measures play an important role in improving students ' autonomy, innovation and practical ability.
\end{abstract}

Keywords-maker education; the Internet space; VR technology; ecology

\section{INTRODUCTION}

Innovation has gradually become one of the benchmarks for measuring social development, and the effectiveness of innovation is tested by entrepreneurship. The MyCOS Research Institute and the Chinese Academy of Social Sciences jointly released the "2017 University Student Employment Report in China”, and the data show that in the past five years, college graduates and entrepreneurship have been nearly doubled from $1.6 \%$ in 2011 to $3.0 \%$ in 2017 . Based on the total number of 7.95 million fresh graduates in 2017, the number of college students enrolled exceeded 200,000 in the year. It can be seen that college students are an important force for innovation and entrepreneurship, and strong innovation ability helps to grasp the opportunities and win the initiative in the fierce international competition. Therefore, maker education has become the current key development object. The development of maker education requires the support of the Internet space. With the help of advanced information technology, the Internet space creates a virtual space for makers to promote teaching, sharing, cooperation and innovation. Then the vast number of makers can exchange learning experiences and share learning experiences through the virtual space. Based on this, the Internet space has become a booster for the development of maker education and the combination of the two has become inevitable. However, the Internet space learning encounters some problems, such as the lack of professionalism and

This work was supported by the Education and Teaching Reform Research Project "The Construction and Practice of the Model of Maker Education under the New Normal". direction [1]. As an advanced technology used in the Internet space, the value of VR technology is closely related to teaching strategy, and it can help solve these problems and conform to the development trend of maker education. But this technology has not been widely used yet. Therefore, how to use VR technology to develop maker education has become an issue that needs urgent attention.

\section{THEORY OF MAKER EDUCATION}

\section{A. Maker Education}

Maker education is a combination of maker culture and education. It advocates creation, encourages sharing, fosters interdisciplinary problem-solving skills, teamwork and innovation based on students' interest in project learning by using digital tools [2]. Many scholars put forward their own opinions regarding the maker education. Yang and Li [3] believe that maker education is a new education model integrating information technology, and takes "creative middle school" as the main learning mode and "cultivating various innovative talents" as the purpose. Zhu [4]considers that maker education has two meanings. In a broad sense, maker education is a form of education oriented to cultivate the spirit of mass maker; and the narrow sense should be an education model oriented to the cultivation of learners, especially the maker literacy of young learners; Zhong [5]insists that maker education is an engineering education, aiming at cultivating students' comprehensive practice.

\section{B. VR Technology}

VR technology, namely virtual reality technology, is also known as "cyberspace", "soul technology", "virtual environment" and so on [6]. It is a technology that uses computers, software and peripheral hardware to generate a immersive environment [7] that can be adjusted and manipulated by the players in real time and provide an immersive experience to users [8]. Then users can interact with the virtual environment to simulate what might happen in order to inspire innovative thinking.

Coiffet and Burdea pointed out that the three most prominent features of VR technology are immersion, imagination and interactivity [9]. Immersion means that users are immersed in a visualized virtual environment as if they are immersive. It breaks the boundaries of time and space and 
deepens the understanding of knowledge in a subtle way, and it is more intuitive, stereoscopic, and effective than the simple flat teaching of the education in stimulating the learners' interest and enthusiasm. Imagination refers to the learners in the virtual real environment spontaneously infer and judge associations, germinate new ideas and perceptions, and feedback to the system. Then the system interacts with learners combining learner status, updates and selects new environmental scenarios in real time, and transmits them to learners again. Interactivity means that learners interact with virtual environments naturally in some instinctive ways such as gestures, movements, eye tracking, speech recognition, expression recognition, and brain waves by manipulating professional VR devices [10].

With these characteristics, the VR technology has been widely utilized in many different areas, such as urban planning, interior design, industrial simulation, multimedia education, and so on [11]. Some experts believe that the 21st century will be the era of virtual reality technology [12]. Therefore, VR technology will rapidly penetrate into the education field with its own huge advantages and potential.

\section{The Internet Space}

Internet space, also known as virtual space, is an Internet-based virtual learning space. Wu [13] believes that the Internet learning space is a virtual territory for teachers and students. It is like a microblog that can create, collect, share learning resources and conduct self-learning management, and also like Moodle, Sakai and other platforms, which can cooperate to learn, provide or obtain others' help and solve problems in a timely manner. Yang and Zhao [14] explain the Internet learning space from the perspective of generalization and narrow sense. The former refers to the virtual space which runs on any platform (QQ space, WeChat platform, etc.) to support teaching and learning activities. The latter refers to the virtual space which runs on a special service platform (National Education Resource Cloud Service Platform, World University City Network Service Platform, etc.) to support the teaching and learning activities. In short, the Internet space is a virtual vehicle that users can share, cooperate, communicate, and achieve self-management and innovation.

\section{INTEGRATION OF VR TECHNOLOGY AND THE INTERNET SPACE}

The integration of VR technology and the Internet space has provided technical support for maker education and formed a new education model.

\section{A. Integration of Development Concepts}

The progress of education needs depend on technology. On one hand, VR technology provides a virtual learning environment where students can enter the environment to observe learning and field operations. VR technology can meet a variety of teaching needs, and its powerful simulation technology can enhance students' initiative and flexibility. On the other hand, the Internet learning space allows students to share their feelings and experiences, and encourages students to actively cooperate and share. The two educational technologies have the same aims: improve students' innovative ability. Therefore, the integration of the two will provide a complete theoretical basis for the development of maker education.

\section{B. Integration of Educational Resources}

The Internet space and education environment can be organized in various forms, which can be individual maker education space or group maker education space, and their goal is to provide a favorable learning environment and rich learning resources and methods for makers. Compared with the Internet space, VR technology enhances the sense of reality. Augmented reality, the development direction that virtual world should vigorously advocate, is based on virtual environment, and enhances the sense of reality of virtual environment through a series of feedback of similar real environment information. For example, the sense of reality in the field of engineering is that when you want to understand the stress and strain distribution of an engineering structure and propose a countermeasure for project structure optimization, VR technology can provide corresponding data by its interactivity. Then users determine the optimal solution based on these data, and it will greatly improve the quality of the project construction.

The Internet space provides a virtual platform, and VR technology introduces a sense of reality. The combination of the two will introduce rich resources for maker learning.

\section{Integration of Teacher-student's Roles}

Teacher-student's roles will change under the maker education. Maker education advocates innovation and attaches importance to students' independent learning. Students are not only the recipients of knowledge, but also the constructors of knowledge, and they need to put forward personal opinions and improve the knowledge system in the process of learning new knowledge. At the same time, teachers become the recipients and guides of knowledge, and they need to constantly update knowledge base, think and design teaching projects that meet the requirements of students. In this process, teachers and students become learning partners, which is also reflected in the application of emerging technologies. The networking space can provide learning resources, and the virtual platform under VR technology will help to enhance the practical ability and cooperation awareness of both parties. Therefore, the integration of the Internet space and VR technology is also a deep integration will enhance the knowledge reserves of teachers and students, and cultivate a complete way of thinking.

\section{Integration of Development Opportunities}

In the era of rapid development of science and technology, more and more fields tend to be informationalized, as does education. Maker education in the Internet space can be seamlessly connected with Internet platforms such as enterprises outside the school and research institutions, and cooperate with makers around the world. At the same time, considering the low cost of VR technology, complete functions, fast information dissemination speed and realism and significant development opportunities, the combination of the two can provide favorable conditions for the promotion of maker education. 


\section{The Development Strategy}

In order to take full advantage of VR technology and the Internet space, we can start from the following aspects.

\section{A. Gain Rich Learning Resources}

Maker education is often based on certain expertise. Firstly, we can use the Internet space to set up online professional courses which combine the maker education with professional courses, then students can choose and study on line within a specified period of time. The theoretical knowledge provided by online courses may be difficult to understand, and students can get rich sensory learning resources by virtue of VR technology. It can transform two-dimensional space into three-dimensional space and transform abstract concepts into concrete objects. For example, students can model the floor plan through VR technology to obtain a three-dimensional human body structure, and define the location of the organ clearly while learning the human body model. Through such a learning process, the understanding and memory of the human body structure can be deepened. Zhang and Feng [15] build a web-based distributed virtual experimental system using VRML and JavaScript. This virtual experiment system can realize the interaction between teachers and students, show students' learning outcomes and help students practice through the web server.

\section{B. Build Online Counseling Space}

The lecturer of the course needs to follow the learning progress of students at any time for guidance, so the cultivation of a professional maker education faculty team is the primary task. Through the learning opportunities and platforms provided by the government and various colleges and universities, we can help teachers master the relevant knowledge of the Internet space and VR technology and expand teachers' understanding of maker education, in order to make them to play the role of teaching and learning better and explore and innovative educational methods actively. In addition, we can build a virtual laboratory by VR technology to provide students with opportunities to interact in the same laboratory with students in different regions, and provide more advanced and convenient conditions for teachers' online counseling. Teachers and students can experiment together on this virtual platform to solve problems in a timely manner, and then teachers can guide students to propose innovative ideas.

\section{Win the Support of the Outside World}

The development of maker education requires not only the support of colleges and universities, but also many external conditions, such as capital investment, technical support, and cooperation platforms. First of all, we can utilize the prospect of both technologies to attract external attention and win more support. Secondly, we can try to communicate with people from all walks of life and in different fields and draw on everyone's unique insights, thinking and rich experience. Then we make full use of social resources to make the innovative ideas of makers more mature, which will have a far-reaching influence on the promotion of maker education. At the same time, the funds raised will be used to promote maker education, introduce advanced technology and attract more makers to participate in the maker movement.

\section{CONCLUSION}

At present, innovative talents are particularly important for economic and social development. Based on the integration of VR technology and Internet space, this paper proposes that the Internet space can provide users with virtual shared carriers and VR technology can be used to enhance the user's realism, so that we can build a new education ecosystem to innovate the development model of education and promote maker education. This paper proposes the following development strategies for the integration of the two. Firstly, we should require rich learning resources and promote individual student development. Secondly, we can build online counseling institutions and innovates the learning methods of teachers and students. Finally, we should try to win the support of the outside world and promote the education of makers.

\section{REFERENCES}

[1] Zhang M, Xia X. Research on the Development Mode and Practice of University Makerspace[J]. The Science Education Article Collects, 2017, (02): 127-128. (In Chinese)

[2] Zhou X, Pan Y. The Connotation, Problems and Countermeasures of University Maker Education[J]. Education Exploration, 2017, (04): 46-50. (In Chinese)

[3] Yang X, Li J. The Potential Value of Maker Education and Its Disputes[J]. Modern Distance Education Research, 2015(02):23-34. (In Chinese)

[4] Zhu Z. From the maker movement to the maker education: cultivating the creative culture[J]. e-Education Research, 2015, (7): 5-13. (In Chinese)

[5] Zhong B. Discussion on Background, Essence, Form, and Support System of Maker Education[J]. Modern Educational Technology, 2016, 26(06):13-19. (In Chinese)

[6] Gao H, Liu S. Virtual reality technology and its application in prevention of coal and gas outburst[C]//Information and Computing Science, 2009. ICIC'09. Second International Conference on. IEEE, 2009, 2: 110-113.

[7] Sacks R, Perlman A, Barak R. Construction safety training using immersive virtual reality[J]. Construction Management and Economics, 2013, 31(9): 1005-1017.

[8] Warwick K, Gray J, Roberts D. Virtual reality in engineering[M]. Institution of Electrical Engineers, 1993.

[9] Burdea G, Coiffet P. Virtual reality technology[M]. John Wiley \& Sons, 2003.

[10] Liu H, Liu L. Research on application scenarios of VR technology in education[J]. E-Business Journal, 2017(05):95-96. (In Chinese)

[11] Li J. Interior design method based on virtual reality technology[C]//Intelligent Transportation, Big Data \& Smart City (ICITBS), 2016 International Conference on. IEEE, 2016: 229-232.

[12] Oxford Advanced Learner's Dictionary [EB/OL]. http://www.oup.com/elt/oald/, 2012-06-06.

[13] Wu Z, Zhao L. Study of Instructional Model of the Flipped Classroom Supported by e-Learning Space[J]. China Educational Technology, 2014(04):121-126. (In Chinese)

[14] Yang X, Zhao X. The Development of Learning Cyberspace: Connation, Phase and Suggestion [J]. China Educational Technology, 2016, (4):30-36. (In Chinese)

[15] Zhang Y, Feng S. Analysis on the Application of VR Technology in the Art Class of Primary and Middle School[J]. Journal of Huanggang Normal University, 2017, 37(01):45-47. (In Chinese) 